\title{
Introduction: traversing the terrain of policy transfer: theory, methods and overview
}

\section{Magdaléna Hadjiisky, Leslie A. Pal and Christopher Walker}

In the classic definition,

policy transfer, emulation and lesson drawing all refer to a process in which knowledge about policies, administrative arrangements, institutions etc. in one time and/or place is used in the development of policies, administrative arrangements and institutions in another time and/or place.

(Dolowitz and Marsh, 1996: 344)

Historically, in the 'age of empire,' this transfer was coercive - often quite literally at the point of a musket or cannon, as the British did in the Opium Wars in the 1800s to open the Chinese market, and subduing the Indian sub-continent. Sometimes, even in the age of empires, the transfers were by choice and in the face of competitive pressures. An extraordinary example of this was when the Ottomans sent 44 students to Paris in 1826 to learn about European science, technology and governance (Al-Tahtawi, 2011; Rogan, 2011). Another was the Japanese after the Meiji restoration (Westney, 1987). However, to the extent that much of human history has been about warfare, conflict, conquest and rule, the coercive 'transfer' of the regimes of the rulers upon the ruled has been routine and unremarkable.

Policy transfer in the modern sense is therefore something different. It assumes the absence of overt coercion. Theoretically, if states are distinct and sovereign, we would not expect - as an initial condition - transfer, emulation and certainly not coercive imposition. Indeed, the analysis of policy making would be quite content to focus on the domestic arenas in each jurisdiction, since external influences or models would be irrelevant. Up until the 1980s, this was indeed the case. Policy studies were still 
coming of age at that time (Radin, 2013), but were clearly influenced by the disciplinary division of labour in political science between domestic and international politics. Policy making was something that took place in the domestic arena; international affairs was about the foreign policy of states.

Despite some antecedents (see below) the policy transfer or 'lessondrawing' literature proper can be traced to Richard Rose's early articles and eventual book, Lesson Drawing in Public Policy (1993), which clearly show that the lines between domestic and international were beginning to blur, and that a purely domestic focus in understanding policy was increasingly inadequate. In Rose's framework, jurisdictions face common problems, and while policy makers may try to avoid dealing with them, eventually dissatisfaction threatens disruption, and they search for lessons. Interestingly, even in admitted cases where powerful states serve as exemplars, it is still a voluntary search by policy makers for those exemplars (Rose, 1991). At root then, this notion of policy transfer as a learning or lesson-drawing process, initiated voluntaristically by domestic policy makers seeking their lessons from epistemic communities and international organizations, became an implicit assumption of the transfer literature. It assumed policy makers in jurisdication A or in jurisdiction B searching for lessons deliberately, consciously, and applying them (in various degrees) deliberately and consciously.

Interest in policy transfer has exploded in the past two decades, due to a number of reasons that have less to do with a placid process of lesson-drawing and more with the imposition as well as disruption of systems, international and domestic. One reason is the increased sense of the interdependence and permeability of domestic policy regimes. The contagion of financial crises and the impact of global 'public bads' such as climate change, make it clear that policy responses increasingly have to be global in nature and localized through transfer, implementation, and reporting. Another - for European analysts at least - has been the European Union's (EU) project of the transfer and adoption of the acquis communautaire, both among member states, accession candidates and in the wider 'European neighbourhood.' Another reason, from another realm, is the development debate. How can developing or near-developed states and economies 'get to Denmark'? What institutions, rules, laws, and policy frameworks do they need to adopt in order to generate both growth and stability? The issue is even sharper with failed states or ones that have been targeted for 'regime change.' According to Michel Foucault, contemporary times are characterized by the passage from a regime dominated by state sovereignties to a regime dominated by the techniques for the government of populations. And indeed, an entire 
global marketplace of ideas and recommendations on 'best practices' has emerged, including international organizations, commissions, donor groups, consultants, think tanks, institutes, networks, partnerships, and various gatherings of the great and the good such as Davos. They may not use the terminology of 'policy transfer' but that, in essence, is what they are debating and selling. The extension of these activities since the end of the cold war has given rise to criticism and concern that this presents a risk for another type of apolitical and technical imperialism (Erkkilä and Piironen, 2014; Grek, 2014; Premfors, 1998).

This book contributes to our understanding of policy transfer by taking a closer, comparative look at the micro-mechanisms of how those transfers occur, when and why they work, and when they do not. The field of the relevant literature is actually richer than might first appear, since the phenomenon of 'transfer' has been considered from various disciplinary perspectives that, for the most part, have remained separate and distinct, even while they address many of the same issues. We can identify at least seven different 'songlines' or pathways that traverse the terrain of transfer, starting from different points and often arriving at different conclusions, but also often overlapping and (sometimes unknowingly) intersecting:

1. Diffusion/learning/policy transfer: Anchored in early work by Wolman (1992) and Rose (1993), and then developed further by Dolowitz and Marsh (1996, 2000), this is a line of analysis focused on public policy dynamics (players, processes, and institutions) and transfer as largely a process of choice.

2. Development and governance: Within the field of development economics, as refracted through international donor agencies such as the World Bank and the International Monetary Fund (IMF), the key question was how to build functioning market economies in Latin America, Africa, and Asia. The 'Washington Consensus' (Williamson, 1993) and ensuing debates (Carroll, 2010; Rodrik, 2006) were explicitly about what economic and political models should be transferred and how.

3. International relations/international governmental organizations: Within international relations theory, the long-dominant realist tradition saw states as the only real actors on the global stage, and international organizations were simply ciphers for the interests of the most powerful state actors. Once this was challenged, international governmental organizations came to be seen as actors in their own right, and a large part of their business is the transfer and 
adoption of best practice policy models and norms (Barnett and Finnemore, 1999; Finnemore and Sikkink, 1998).

4. Global public policy networks: Closely related to the previous stream of literature, and to some extent in more explicit dialogue with it, is the recent work on global policy networks that act as channels of ideas and models (Haas, 1992; Stone, 2013). These networks can include international governmental organizations, but non-governmental organizations (NGOs) and other idea brokers as well.

5. Europeanization: The EU project has been one of developing supra-national institutions and policy frameworks, laws, regulations and standards that apply - with a variable architecture and content that is sensitive to local and national distinctions - across and within all member states (Leuffen et al., 2013). An important tributary within this stream of literature is the analysis of the policy transfer to central and Eastern European states after the collapse of communism (Jacoby, 1999; Schimmelfennig and Sedelmeier, 2005b).

6. Policy mobilities: This is one of the most recent contributions to transfer studies, though self-admittedly 'somewhat inchoate' (Peck and Theodore, 2015: 5). It tries to capture analytically the increased intensity and velocity of policy transfers in an era of 'instantaneity of connectivity of sites, channels, arenas' (ibid: 223) and of 'porosity of policymaking locales' (ibid: 224)

7. Socio-political conditions of policy transplantation: Inspired by sociology and social history, this last contribution defines itself in contrast to rational-technical models of transfer (the policy transfer/ diffusion literature above), focusing instead on the institutional, political and cultural environments within which transfer takes place.

The next section discusses each of these approaches, drawing out strengths and weaknesses, as well as transversal themes. That is followed by a discussion of the methodological approaches taken in this book, and a summary of the chapters.

\section{POLICY TRANSFER: APPROACHES AND FRAMEWORKS}

\section{Diffusion, Learning and Policy Transfer}

The first seeds of the policy transfer literature germinated in the political science research on the diffusion of legislation among American states (Gray, 1973; Walker, 1969). This was about intra-state transfer of 
legislation and policy models, and was less interested in the mechanisms of transfer than aggregate patterns of diffusion and the logic of policy innovation among leaders and adopters within a federal state. The assumption that federal forms of government permit and even invite experimentation at the sub-national level provided a natural testing ground for transfer, and the same logic applies now in analyses of the European Union, where a quasi-federal system also permits, in principle, experimentation and innovation in the implementation of EU law and policy (Sabel and Zeitlin, 2010).

The diffusion approach was modified and applied to comparative analysis across states, and recast in terms of policy transfer. Arguing that policy transfer was 'an under-researched field about which very little is known', Wolman (1992: 29-30) listed a set of key questions that continue to drive the field (e.g., how do ideas for policy transfer enter the domestic policy process?). By doing so, the policy transfer literature distanced itself from the initial diffusion framework. As Stone puts it the "diffusion" literature suggests that policy change occurs by osmosis; something that is contagious rather than chosen. It connotes spreading or dispersion of models or practices from a common source or point of origin' (Stone, 2012: 3). The diffusion approach has been criticized for overlooking the different agencies and political interests involved in transfer, though this is somewhat unfair in light of work on the rational calculus of adopters in the diffusion process (Weyland, 2006). Nonetheless, by analyzing international diffusion as a process, the transfer literature assumes, on the contrary, that the way in which the policy transfer occurs is important in understanding its nature and outcome.

In various articles, Dolowitz and Marsh developed this idea and framed it more directly in terms of 'policy transfer' (Dolowitz and Marsh, 1996, 2000; Dolowitz, 2009). Their key contributions were to expand the notion of lesson-drawing to include coercion, fear, and herding (Dolowitz, 2004), and also to begin to map out the different actors and organizations that might be involved in transfer processes. They highlighted all the key questions and issues: (1) degree of coerciveness (voluntary, mixed, coerced); (2) actors (elected officials, bureaucrats, NGOs, intergovernmental organizations, think tanks, etc.); (3) what is being transferred (policies, instruments, programs); (4) sources (intra- and crossjurisdictional); (5) types or degrees of transfer (copying, emulation, inspiration); and (6) constraints on transfer (Dolowitz and Marsh, 2000: 9). The impact of globalization, communication and information flows, and particularly of international governmental organizations, "meant that policy-makers increasingly look to other political systems for knowledge and ideas about institutions, programs and policies and about how they 
work in other jurisdictions' (Dolowitz and Marsh, 2000: 7). Outcomes of the process were uncertain however, because of the combination of external pressures and internal dynamics (Stone, 2012: 3-4).

A substantial stream of work flowed from these early contributions (Dumoulin and Saurugger, 2010; Evans, 2009, 2004; Evans and Davies, 1999; Marsh and Sharman, 2009; Massey, 2009), and while the Dolowitz and Marsh framework included both voluntary and coercive transfer, as well as a range of influences and factors such as institutions and ideologies, the prevailing view in this literature was that the 'study of policy transfer analysis should be restricted to action-oriented intentional learning: that which takes place consciously and results in policy action' (Evans, 2009: 244). This particular bias, as well as others (i.e., rationalist, pluralist, and positivist) were noted by critics (Benson and Jordan, 2011, 2012; Dussauge-Laguna, 2012) but for our purposes the primary oversight was in neglecting the 'micro-dynamics' of transfer, in exploring more fully the mechanisms of translation, appropriation, and even resistance. Other frameworks can help in this regard.

\section{Development and Governance}

Whereas the policy transfer literature proper grew out of political science and policy studies (with a strong UK flavour), an entirely different and more applied literature arose in the field of development economics and the work of the World Bank and the IMF. Both of these institutions had a mandate to strengthen the global (capitalist) economic system, initially with a focus on developing economies, and later, the transitional economies of the former Soviet Union. The early focus on encouraging market-based economic growth was later joined by recipes for governance and public sector reform. These transfer efforts were characterized as the 'Washington Consensus' (Carroll, 2010; Rodrik, 2006; Williamson, 1990), and criticized for various epistemological and organizational reasons (Clegg, 2013; Moyo, 2009; Moretti and Pestre, 2015; Murphy, 2007; Park and Vetterlein, 2010; Peet, 2003; Woods, 2006; Xu and Weller, 2009).

Without using the conceptual apparatus of policy transfer, this body of work nonetheless highlights some important points. The first is the role of international governmental organizations, though in this case specifically a handful of extremely prominent ones with disproportionate influence. The second is the emphasis on the object of transfer - a broad policy paradigm (the 'Consensus'), as well as its instruments, programs and implementation strategies. In some cases, while transfers may be instrumental, in others they can be an amalgam of broad theories and 
their specific tools (e.g., free markets exemplified in an absence of currency controls). A third point is policy failure and resistance. Ideological opponents could be expected to be critical of the World Bank and the IMF, but they are joined by apostates (Easterly, 2006, 2013; Griffiths, 2003; Stiglitz, 2003, 2006) who have diagnosed development disasters (i.e., failed transfers) from within. They hence join some early French comparative politics studies, which warned against the illusion of thinking that the diffusion of Western governance models could be achieved without rupture in developing countries (Badie, 1992; Rist, 2007).

A fourth element of this literature is how it has evolved from a focus on economics and building markets, to governance and effective public institutions. It took the World Bank about a decade to see the relevance of the state to economic development (World Bank, 1983, 1997). As Roberts points out, before

the 1990s, many development specialists, particularly those affiliated with major organizations like the World Bank, paid little attention to the ways in which the design of state institutions affected economic growth. But this changed in the 1990s. The World Bank in particular developed an enthusiasm for the improvement of 'institutional capability' in poorer nations.

(Roberts, 2010: 15)

A clear line of work in the development field sprang from this somewhat banal insight, but has led to fundamental work on the nature of the state and governance (Fukuyama, 2004, 2013; Holt and Manning, 2014), as well as ways to measure various elements of governance systems (Arndt and Oman, 2008; Rotberg, 2015; Davis et al., 2012). Success has been elusive, leading to hypotheses about failure that probe what is in effect the nature of the transfer and the actual fidelity to the models allegedly being adopted (Andrews, 2013; Pritchett et al., 2012).

Finally, in a related but distinct field of inquiry and analysis, there is the mountain of governance work around 'new public management' (NPM) as a recipe for public sector reform. NPM-inspired reforms experienced a surprisingly quick inter-state and international dissemination and prompted an abundant body of academic literature about its content, its success and failures, and its possible successors (Barzelay, 2001; Christensen and Laegreid, 2002, 2007, 2011; Hood and Peters, 2004; Lane, 2000; Pollitt and Bouckaert, 2011; Pollitt et al., 2007). After an initial phase of enthusiastic assertions (though see Hood [1991]) about an emerging global convergence (McLaughlin et al., 2002; Jones et al., 1998; Kettl, 1997), a growing number of scholars have interestingly emphasized the need for contextualization, focusing attention on the 
interaction between the doctrine or instrument transferred and the place, the context, to which it is being applied. Sometimes NPM reforms have been simply legitimization exercises (Radaelli, 2004), but in all cases reform outcomes vary because of pre-existing institutional and political paths (Bezes, 2010a; Pollitt and Bouckaert, 2004, 2011; Suleiman, 2003), combined with the game played by the contemporary political and social actors of reform (Christensen and Laegreid, 2002; Hood and Jackson, 1991; Hood and Peters, 2004).

Together, this body of work represents a coherent field of inquiry about policy transfer, though it rarely uses the term. However, it highlights in detail, and with a particular accent, the role of international governmental organizations, their attempted transfer of massive ideological templates, and the enormous work around state development and public sector reform.

\section{International Relations and International Governmental Organizations}

Both the early diffusion and transfer literatures focused on state actors, and policy movement across their jurisdictions. This naturally abuts the field of international relations, though the dominant realist tradition within that field had treated states as unitary actors, and was not particularly interested in the domestic impact of international events or agreements. The linkages between domestic public policy arenas and international forces attracted attention in the 1980s and 1990s (Doern et al., 1996; Putnam, 1988), and was reinforced by social constructivist approaches that emphasized the role of non-state actors and ideational frames as the basis of stable international regimes. This was a vision of international affairs with many more actors, all interacting with and through states in the development of both domestic and international public policy.

Several developments in international relations consequently fed into work on policy transfer. One was the role of government agencies or other state organizations that operate with substantial autonomy within focused policy areas, marshalling expertise, exchanging information, and often generating operational agreements (Biermann and Siebenhüner, 2009; Slaughter, 2004a, 2004b, 2004c). These are often the 'bureaucrats' mentioned in various policy transfer models, but in many cases they are bureaucrats with an international mandate or at least international partners and interlocutors. Another contribution was the work on the role of non-state actors: NGOs, private sector firms and associations, epistemic communities (scientists and researchers, think tanks), foundations, and 
others (Cutler et al., 1999; Haas, 1992; Keck and Sikkink, 1998; Khagram et al., 2002; Stone, 2004, 2008). They are not merely observers or pressure groups; they are increasingly involved in both policy development and administration, often engaged directly with states as partners or in distinct realms of non-state regulation (Büthe and Mattli, 2011; Cashore et al., 2004; Christensen, 2006; Ronit, 2007). Stone recognized the relevance of this work, and self-consciously highlighted its importation from international relations theory (Stone, 2000).

A particularly significant contribution was the role of international governmental organizations. The realist model had viewed these organizations as the simple expression of the interests of their strongest state members, but the new analysis began to see these organizations as having a distinct set of institutional interests and agendas (Barnett and Finnemore, 1999, 2004; Deacon and Hulse, 1997; Deacon et al., 1997; Finnemore and Sikkink, 1998; Ougaard, 2010). More recent work has analyzed the internal dynamics of these organizations, and the ways in which they orchestrate, coordinate, and transfer global policy regimes (Abbott et al., 2015; Koppell, 2010; Trondal et al., 2010).

This area has been one of the most fertile for policy transfer studies, but has often required 'non-international relations' scholars to traverse the disciplinary boundaries and research unfamiliar actors and organizations. By now, however, there is a rich accumulation of research on these players and their role, singularly and in concert, in both developing policy ideas and spreading them globally and in domestic jurisdictions.

\section{Global Public Policy Networks}

A closely related but distinct field of study relevant to policy transfer has been work on global policy networks. These networks often consist of the actors and players identified in the previous section, but the research here has made three distinct contributions. The first is on the role of ideas and their 'carriers' in transnational policy development, the classic formulation being 'epistemic communities' (Haas, 1992). To the degree that all policy makers are searching for solutions to problems, they will search for ideas, facts, theories, explanations - a complex amalgam that sheds light on the policy problem and provides models or experiences as solutions (sometimes borrowed from elsewhere) (Dunlop, 2009). An obvious repository of such policy relevant knowledge will be credible 'experts,' usually distributed in research institutes, think tanks, specialized non-governmental organizations, consultancies, associations, foundations, and international governmental organizations. 
The second contribution is to assess this expertise and this knowledge critically. When policy makers are searching for inspiration, they have their own blinkers, hidden or even unconscious motivations, and other lenses. The 'suppliers' of ideas - various epistemic communities - have their own limitations, blind spots, preferences, assumptions, and motivations. Some actors have more resources or credibility than others (e.g., the Open Society Foundation, the OECD), while some have managed to dominate their policy terrain (e.g., Transparency International around anti-corruption). Simply acknowledging the existence of global public policy networks does not presume that they are purveyors of some unchallenged truth. The research implication is that one has to conduct a careful sociology of these networks to understand their influence and their dynamics.

The third insight is that most of the 'suppliers' do not act alone. They engage with each other and with states through networks. As an organizational form, networks have special features that distinguish them from the more traditional, hierarchical (state) bureaucracies that tend to dominate most domestic policy making (Barabasi, 2000; Börzel, 1998; Dowding, 1995; Enroth, 2011; Freyberg-Inan, 2006; McNutt and Pal, 2011; Watts, 1999, 2003). Of the many characteristics, we can highlight two (for more detail, see Pal, 2012: 19-20). One is that these networks are 'recombinant' and fluid, they move and morph in semi-random ways, adapting to their circumstances and environment. The second is that network links and connections consist of exchanges, and in global public policy networks the medium of exchange is information, data, knowledge. Simply taking these two characteristics, we can see how policy transfer from this perspective would be much more fluid, non-linear, and distributed than would have been predicted in earlier models that (unconsciously) relied on traditional organization theory.

\section{Europeanization}

Europeanization refers to:

Processes of (a) construction (b) diffusion and (c) institutionalization of formal and informal rules, procedures, policy paradigms, styles, 'ways of doing things' and shared beliefs and norms which are first defined and consolidated in the making of EU decisions and then incorporated in the logic of domestic discourse, identities, political structures and public policies.

(Radaelli, 2003: 30) 
The study of 'Europeanization' is thus a natural point of contact with the policy transfer literature. Both frameworks insist on the processual character of the phenomenon and focus on the role of actors at the different jurisdictional levels (mainly here international/European and national).

This field of research has focused on 'adaptation pressures' and has studied the levels and types of 'fit' and 'misfit' between European policy requirements and existing institutions at the national level of member and non-member states (see e.g., Börzel and Risse, 2003; Cowles et al., 2001; Mastenbroek, 2005; Olsen, 2002). The collapse of communism and the sudden appearance of central and Eastern European states as potential EU members, states that had been cut off from the European mainstream for almost 50 years, constituted a great challenge and an opportunity for Europeanization research. In order to accede to the EU, candidates must meet the standards outlined in the acquis communautaire, and indeed there is a pre-accession phase where the EU and other organizations assist candidates in reforming their institutions and policies. As Schimmelfennig observed that

In the aftermath of the Central and Eastern European revolutions and the breakdown of communism, the CEECs [Central and Eastern European Countries] have turned to international organisations for guidance and assistance in their political and economic transformation, and international organizations have become strongly involved in the domestic politics of the CEECs, the restructuring of domestic institutions, and the entire spectrum of material policies.

(Schimmelfennig, 2002: 1)

These organizations played an 'unprecedented, active role' in promoting democracy and market reforms (Smith, 2001: 31). A cottage industry grew up around the analysis of the success/failure of 'transition' in the formerly communist states (Carothers, 2002; Jacoby, 1999, 2001; Nunberg, 1999). After 1989, Europeanization research progressively extended to non-member states (Schimmelfennig and Sedelmeier, 2005b). Subsequently, a new trend of research emerged trying to fruitfully combine Europeanization and transfer studies in identifying the spread of EU institutions internationally (Börzel and Risse, 2012a).

The more recent Europeanization literature is too large to summarize here, but it has continued to reflect on the challenges of spreading European norms in the 'Neighbourhood countries', in newly acceded states, reinforcing those norms among existing members, and exploring domestic impact of rules and policies made in Brussels (Cowles et al., 
2001; Delcour, 2011; Dimitrova, 2010; Epstein and Jacoby, 2013; Knill, 2006; Leuffen et al., 2013). This rich literature has elaborated some clarifications and analytical frameworks which can be fruitful for studying international transfers in very different social and territorial contexts. A 2006 special issue of Revue internationale de politique comparée (vol. 13 [2]) and a 2012 special issue of the journal West European Politics (vol. 35 [1]) explicitly connected the question of Europeanization to the literature on policy transfer and diffusion.

The first collection highlighted the point that the policy transfer framework addresses one frequently noted methodological issue: in the Europeanization literature, changes at the domestic level are attributed to European pressure without always taking into account other possible sources of policy evolution (e.g., economic trends, private firm interests, institutional borrowing between individual member states, international actors influence, etc.). However, it is often difficult to evaluate the specific part of the EU in the phenomena observed at the local or national level (Thatcher, 2014). The policy transfer framework helps leave the 'EU-ization' focus behind and situate the European Union within its wider international context.

As the editors to the second special issue concluded: there is 'ample evidence for the EU's influence on domestic and regional institutions. Its impact is patchy, often shallow but certainly not spurious. ... the EU has influenced institutional change even where its shadow of hierarchy is weak or non-existent' (Börzel and Risse, 2012b: 194-195). The EU is a fascinating case, since it has both 'hard' tools (conditionality) and 'soft' ones (capacity-building and technical assistance), and the range of country cases provides laboratories to explore the dynamics of transfer and diffusion. Several of the key findings from the 2012 special issue mirror points made above: (1) pure mimicry is rare; (2) the EU is never a passive bystander in transfer processes, instead using a host of institutions and epistemic communities (particularly lawyers); (3) EU initiatives are often blocked or resisted through informal institutions, rentseeking, or clientelism; (4) supportive domestic coalitions are essential for success, but not always present, and indeed the Europeanization process can empower opposition groups; and (5) 'receiving states' often do not have the capacity ('limited statehood') to implement reforms. The editors conclude that one of the key lessons from the Europeanization literature for policy transfer and diffusion studies is the 'role of agents in diffusion processes.' Diffusion (and transfer) should be conceived as 'active processes of selective adaptation whereby the targets are not passive recipients, but active shapers of institutional change' (Börzel and Risse, 2012b: 204). 
One of the strongest trends in the Europeanization research is the re-estimation of the role of domestic actors, frames (Cowles et al., 2001; Palier and Surel, 2007) and bottom-up processes (Baisnée and Pasquier, 2007). Diffusion (and transfer) should be conceived as 'active processes of selective adaptation whereby the targets are not passive recipients, but active shapers of institutional change' (Börzel and Risse, 2012b: 204). This re-evaluation of inside actors and configurations in Europeanization processes has to be related to the persistent variety of national paths, despite a similar European pressure for adaptation emanating from a particularly strong (supranational) actor. This book has several chapters on the EU and the general point of taking the measure of micro-dynamics and of the local actors' role is reflected throughout.

\section{Policy Mobilities}

This 'pathway' in transfer studies has proximities with urban geography, and the notion of 'policy mobilities' (McCann and Ward, 2011) sees itself as concerned with 'entrepreneurial governance, urban social movements, gentrification, policing, planning and redevelopment' within the context of the 'social reproduction of cities' (Baker and Temenos, 2015: 825). While marked by a range of methods (Kennedy, 2016), proponents see both a challenge to, and a possible synergy with, conventional transfer studies (McCann and Ward, 2012; Peck, 2011).

Peck and Theodore admit that the approach is 'inchoate' but nonetheless oppose it to what they perceive as the rationalistic, technical and linear approach in the transfer and learning literature: 'the movement of policy is more than merely a transaction or transfer, but entails the relational interpenetration and mutual interdependency of policymaking sites and actors' (Peck and Theodore, 2015: 5). Their notion of 'fast policy' tries to capture what they claim is both the increased intensity and the velocity of policy transfer.

This approach is interestingly more attuned to transfer in the context of (neoliberal) crisis and coercion than the early transfer literature was. On the other hand, the development and governance literature has addressed these issues, simply because development paradigms have been typically about 'big change.' Some of the Europeanization literature has also registered the challenge of broad 'system change' that goes well beyond trading in policy tools. Indeed, the 'fast policy' approach reminds us that the backdrop to the global policy transfer theatre, since at least 2008, has been the crisis of neoliberalism. This is one reason why transfer seems to have gathered 'velocity' and 'intensity,' and we would add, 'density.' In other words, many contemporary transfer processes are indeed about 
learning and search, but in a context of deep angst about the viability of broad systems - contemporary capitalism, liberal democracy, the EU, or the balance between North and South. This drives the pace of transfer, makes it more frantic in some instances, more intense and desperate in others, and possibly more marked by conflict and coercion.

\section{Socio-political Conditions of Policy Transplantation}

Inspired by sociology and social history, a last series of studies analyzes international mobilities as inter-social mobilities: the way actors interpret and use (or not) the object of transfer depends on the social space in which they are embedded, in which they work and live. Even in a period of 'fast policy,' to be interconnected is not sufficient: 'Linkages may be cultural as well as relational. (...) The individual or organization's cognitive map identifies reference groups that bound social comparison processes. Rational mimicking requires prior and potential adopters to be understood as fundamentally similar, at least with respect to the practice at issue' (Strang and Meyer, 1993: 490-491). These studies are diverse by their subject: they deal with the international 'circulation' of academic texts (Bourdieu, 2002) or of institutional instruments and doctrines (Hadjiisky, 2007; Kaluszynski and Payre, 2013), they explore the cultural conditions for diffusion (Strang and Meyer, 1993), or the appropriation and local adoption of globally generated ideas and strategies, for example women's rights (Levitt and Merry, 2009). Nevertheless, far from deriving from a mere attention to detail, contextualization is essential to an understanding of the phenomenon in itself.

Transfers resemble transplantations, which are deeply dependent on the variation of institutional, political, cultural, contexts. Identical external incentives can produce different outcomes in different political and/or social areas. This is because, as stated by Peck and Theodore, who share this context-sensitive approach, transfer processes do not operate unidirectionally from the 'capitals of innovation to hinterlands of emulation' but relationally and interdependently (Peck and Theodore, 2015: 7).

As conclusions from this approach, these might seem somewhat banal, but they do register some important developments in transfer theory, ones with which this book is broadly in agreement.

First, while the Dolowitz and Marsh framework was considerably more subtle than a simple rational-technical model of spreading best practices (Dolowitz and Marsh, 2012), it is true that its original inspiration (especially coming from Rose) was in learning, lesson-drawing, and 'problem-solving.' 
Second, the processual, uncertain and context-sensitive character of policy transfers strongly pleads for placing the micro-processes and actors' configurations at the heart of the analysis. They are not factual details but help us understand what is really going on. Actors and agency matter as much as process and structure. Research needs to identify the actors involved in the process, at all levels (local, national, trans- and inter-national). Bureaucratic and institutional (domestic and international) actors play an important role, but elected politicians, private interests, social actors, media, consultants, think tanks, foundations, are also important, as are their networks. Our approach is in contrast with other conceptual traditions ('diffusion,' institutional isomorphism), which consider the results (convergence, divergence, innovation ...) more than the process and try to link this outcome with one structural macro-factor (as for example, the classical quantitative comparisons linking democracy with a certain level of economic growth).

Third, our approach, to the degree that it draws on 'critical policy studies' (Fischer et al., 2015; Orsini and Smith, 2007), emphasizes discourse, language, 'discursive frames,' and policy paradigms, an emphasis well-reflected in some branches of transfer theory. To this extent, there is yet another, more sotto voce songline in the field that emphasizes the impact of policy paradigms (Skogstad, 2011) à la Peter Hall (Hall, 1993, 2013), and another that - taking discourse and the linguistic and cultural framing of policy seriously - sees transfer as 'translation' (Clarke et al., 2015; Djelic and Sahlin-Andersson, 2006; Prince, 2010: 173; Sahlin-Andersson, 1996; Steiner-Khamsi, 2014; Stone, 2012), 'appropriation' (Bayart, 1996) or even 'vernacularization' (Levitt and Merry, 2009). These notions prevent us from 'turning objects, ideas or projects into black boxes assumed to travel unchanged across different universes' (Dumoulin and Saurugger, 2010: 24). Transfer actors are not considered as simple brokers of turnkey solutions; they are also translators not so much as linguist (even if this can be part of the story if the passage from one language to another is needed) but because they are able to reframe the initial proposition in a socially and politically meaningful way for the populations concerned.

If Rose, and then Dolowitz and Marsh, were the first cartographers of a new continent of policy transfer, we might say that their original maps were good enough to get our bearings, but need more detail to enable further navigation. The various literatures we have reviewed above provide those details, and this book takes them several steps further. Figure I.1 illustrates how the original elements of the Dolowitz and Marsh framework have been elaborated by the various literatures discussed above. 

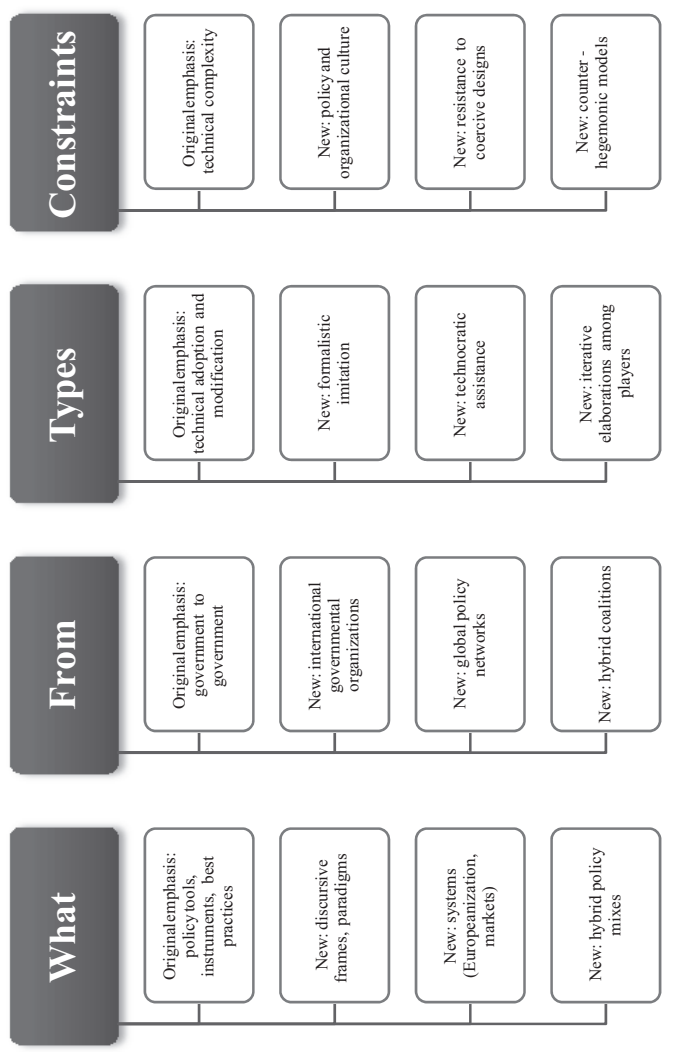

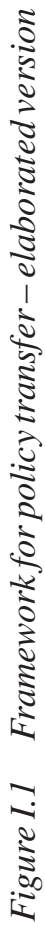

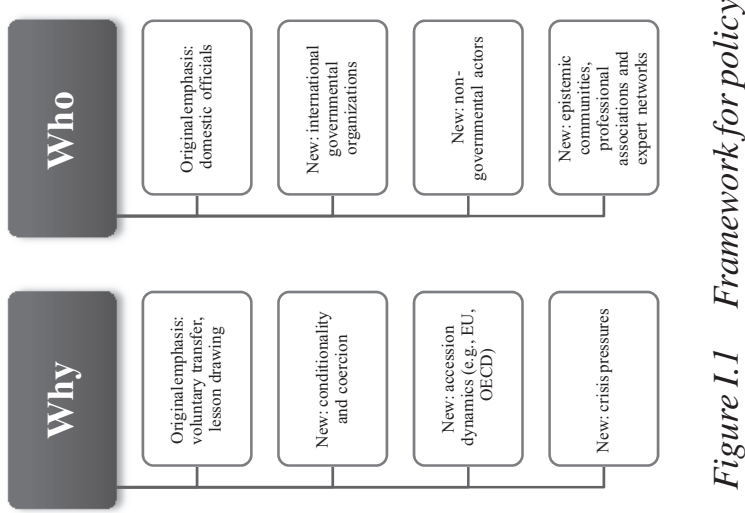


In order to compare international transfers in different processes of dissemination, this book is not limited to a single field of public action, or to a specific geographical area. Despite this empirical diversity, it is highly consistent in method. Chapters focus on the study of microprocesses and the configurations of actors, interests, and representations to provide insights into the phenomena under consideration. By considering international transfer as a field of study in its own right, the contributions open the 'black box' of how change results in a policy interdependent world. An interesting feature of this volume of work is that it highlights a renewed interest in participatory field research and showcases the analytical insights that can emerge from this form of qualitative research. The next section presents the methodological approaches adopted by our authors.

\section{OUR PROCESS OF ENGAGEMENT AND METHODS OF ANALYSIS}

This book reflects a highly collaborative and engaged approach, both with the policy cases and actors that are the central focus of analysis in each chapter, as well as amongst the authors and editors. The project began with panels at the International Conference on Public Policy held in Milan in July 2015. We are grateful to David Dolowitz who provided insight and commentary on the original papers. Six months after the Milan conference, the authors again met in Strasbourg to jointly debate common thematic links. This critical and supportive process has been central to drawing out insights and findings from the case studies presented in this volume. As we studied the transfer of policy ideas and practices across nations, we ourselves engaged in a trans-global process of debate and analysis linking scholars from North and South America, Australia and Europe.

Each of the chapters applies a mixed qualitative methodology to the policy transfer cases being discussed. While there is a generally consistent approach that draws on interviews with key informants and the analysis of policy documents, rules, regulations, parliamentary debates and relevant reports, each study demonstrates particular nuances in its methodology that highlights both the importance of context when studying policy transfer, as well as the breadth and adaptability of qualitative techniques. The multifaceted nature of qualitative research (Bryman, 2012; Denzin and Lincoln, 2011; Silverman, 2010) produces detailed and nuanced findings of contextual relevance that can inform wider theoretical understandings (Marsh and Sharman, 2009; Tracy, 2012). Behaviour, 
ideas and responses to problems can be understood in the context of local systems and their meanings (Bryman, 2012). This is particularly helpful when trying to understand factors that influence decision-making and choices about policies, and their adoption and modification. For this book, the strength of our analysis and findings is the deeply rooted nature of our methodology in high quality case studies.

Many of the case studies in this volume involved travel to 'adopting' countries and engagement with local organizations. Unique to this volume is a body of work that examines transfer cases from North-toSouth as well as South-to-South, allowing the exploration of challenges and characteristics of transfer and engagement across emerging economies (see chapters by Milhorance, Porto de Oliveira, Zardo, and Walker). Our authors address the general shortcoming identified by Marsh and Sharman regarding the 'reluctance of scholars to travel too far from their home base to examine the experiences of policy-makers on the receiving end of Western models' (2009: 281).

All our authors have travelled extensively to inquire and understand processes and forces that shape policy transfer across unique governing domains. In some cases, relationships and pathways for engagement have evident historic legacies. In other cases, emerging networks of actors, new leaders and shifting political contexts create opportunities for policy discussions and open opportunities for policy transfer. Many of the chapters examine the nature of international and local actor interaction, seeking to understand how relationships between transfer agents shape policy transmission and local adoption. Looking at the roles and interaction of actors and their agency moves the analysis beyond a simple institutional analysis. Participant observation and semi-structured interviews help the researcher develop a deeper understanding of this complex interaction and how it may shape the iterative process of policy transfer.

This methodology gives access to micro processes that may be shaping local action as well as an understanding of macro factors. For example, the Porto de Oliveira chapter traverses nine countries and draws on 125 participant interviews, while Delcour's draws on data from two research phases over a four-year period of location visits, interviews and observations. Some authors undertook participant observations at implementation meetings, training forums and consultations between public agencies and civil society organizations. Milhorance's draws on over 200 interviews and the author's experience from a seven-month placement in a local organization. This deep level of engagement and participant observation supports a social network analysis that aims to reconstitute the processes and networks of social exchange among key participants. Several chapters show a high level of access to EU organizations and the 
close scrutiny of their reports, rulings, model laws, standards and regulations.

In this book, the case study is the standard unit of analysis to both locate and analyze the policy transfer process. Case studies provide an opportunity to delve into the deeper detail of an issue and build a more elaborate understanding. This approach has been instrumental in drawing out the micro-analysis of the transfer process that is documented in many of the chapters. Building a detailed understanding of a case also assisted the authors in understanding the cultural and institutional factors that come into play as policy programs, models and systems transfer from one location of governance to another. This approach facilitates a mapping of the complex dynamics between actors involved in transfer processes, either as supporters of change, translation and transfer, or moderating forces of resistance.

Although traditionally associated with qualitative research methodologies, case study analysis can involve both quantitative and qualitative data (Gerring, 2007; Yin, 2012). They may be small or large-N studies as the range in sample sizes in this volume demonstrates (Gerring, 2004: $353)$. According to Yin $(2012,2014)$, case study research is an essential form of social science inquiry that engages with the complexity and extensiveness of the everyday context. Case studies permit an investigation into a contemporary phenomenon (the 'case') in its real-world context (Yin, 2014: 16-17). Our authors have drawn heavily on this methodology to understand the everyday context that provides the evidence of policy transfer. Case study research is known to constitute an 'intensive study of a single unit for the purpose of understanding a larger class of (similar) units' (Gerring, 2004: 342) and this in part, reflects an objective of our book. In this volume we present a range of intensive case studies as part of a broader effort to build our knowledge of policy transfer and the role of micro- and macro- processes. So, while case studies are characterized by the relatively small number of instances ('cases' or 'units') involved in the study, the act of performing detailed analysis across a range of settings should help us derive a number of generalizations regarding the process of policy transfer (Vogt et al., 2011: 299).

Nevertheless, the applicability of specific knowledge obtained through a focused case study remains contestable and a key challenge for the validity of case study research. Vogt et al. (2011: 310) describe this as 'fruitful tension between the particular and the general,' and for this book the micro-detail revealed through case study is balanced against the macro-understandings that emerged from the research. For some critics of this approach, the particular nature of case study data means that 
findings cannot be generalized to other contexts (Gerring, 2007; Marsh and Sharman, 2009). The specific focus of case study research can also be seen to produce 'inferences with poorly defined boundaries' (Gerring, 2007: 347). Yin (2012: 6) responds to this criticism arguing that the inclusion in case study research of systematic data collection and analysis procedures enables findings to be applied to other situations through analytical generalization. This is a methodological challenge that this book aims to address. Our goal is to contribute to an understanding of what shapes the long and iterative journey of policy transfer, shaped by the action around policy analysis, adoption, implementation and practice.

\section{OVERVIEW OF THE BOOK}

This book is graced by an unusually wide range of cases in terms of actors, policy fields, and countries. Our concluding chapter draws out the detailed advances that they contribute collectively to the field of policy transfer studies, but for purposes of exposition we have organized them into two parts.

The first is a group of chapters that 'bring local actors back in.' They remind us that the 'recipients' of transfer are much more than that; they actively shape the transfer process through bargaining, cooperation, translation, and resistance, and that the process often reflects competing frames of reference. Thierry Delpeuch and Margarita Vassileva's chapter examines rule of law and judicial reform in Bulgaria, an effort that had to deal with the legacies of communist institutions as well as elites. They focus on the dominant role of American donors and operators, a dominance that they argue was due to a quasi-hegemony over policy expertise and local knowledge, but also to an ability to build local coalitions of support. When the Bulgarian government in 1997 decided to seek EU accession, it sought technical advice on judicial and rule of law reforms. While European institutions and norms clearly played a role, Delpeuch and Vassileva argue that American transfer agents (including USAID and the World Bank's experts) soon achieved prominence through: (1) large amounts of financial aid; (2) the capacity to deliver decentralized but coordinated cooperation initiatives; and (3) superior technical expertise on the mechanisms of the Bulgarian judicial system, built up over a decade of careful analysis and measurement. EU institutions (and member states), while also active in this 'transfer theatre,' lacked these resources, and eventually accepted the American framework as a basis for accession negotiations. Moreover, Delpeuch and Vassileva highlight how the Americans were fully aware that their 
'technical' reforms - which would buttress the independence of the judiciary - would threaten powerful interests, such as prosecutors and magistrates. To address that, they worked to support or create 'allies' in civil society, professional associations (e.g., the Bulgarian Judges Association), and business groups.

The chapter by Cécile Vigour highlights the leading role played by local actors and professional groups in selecting and adapting policy instruments. An important feature of this chapter is that it draws a clear link between forces of policy transfer and the imposition of governance and administrative reforms shaped by NPM ideals. The chapter provides a macro overview of management reform across the French public sector and then examines the introduction of 'Lean management' into the operation of the French judicial system. This involves the translation and implementation of private sector management practices into a judicial, public sector service dominated by professions. In this case we see the micro-dynamics of policy transfer play out as influential private sector actors work with both willing and resistant professional groups and civil servants to reshape the management and efficiency of French courts. The case highlights how transfer and translation occur within a broader framework of managerial reform. An important finding is the role of transfer agents who have a capacity to understand both the originating context and the implementing context of the policy. Consultants with credible public sector experience, effectively with a 'foot in each camp,' were able to reshape implementation through bottom-up engagement. Resistance to policy transfer provided an opportunity to reshape and reinterpret and eventually reinforce successful implementation. A valuable insight of Vigour's sociological analysis is that actor characteristics influence the policy transfer process. Her chapter identifies the unique behaviour and responses of professions (judges and lawyers) as critical in contributing to the success or failure of policy transfer.

Christopher Walker's chapter examines policy transfers to the Global South, in this case from Australia to South Africa in the field of road transport (trucking) regulation. The original Australian policy framework was the National Heavy Vehicle Accreditation Scheme (NHVAS), adopted in 1999, designed to protect road infrastructure and improve the safety performance of truck operators. Its success attracted the attention of South African regulators and industry, and in 2003 they adopted a modified version of the NHVAS entitled the Road Transport Management System (RTMS). Both schemes are organized as voluntary industry self-regulation, audited and overseen by state regulatory authorities. However, whereas the NHVAS is fully funded by the national regulator, the RTMS has industry membership fees which are expected to cover the 
operational costs and administration of the scheme. As well, the governance structure for the RTMS is based on a steering committee with a broad representation from industry and government agencies. Walker's chapter shows that a key factor in the South African modification of the Australian design was concern about state corruption. The incapacity and corruption of the state in South Africa required a scheme run and funded by stakeholders themselves, with some government participation, but not control. This also encouraged the development of creative market-based incentive systems in South Africa. The result was policy transfer from a state-dominated model to a market-based one, from government regulators to industry-based stakeholders. This is an important contribution to our understanding of transfer dynamics, and Walker adds to it by pointing out that feedback loops potentially run through the South African experience back through global transportation policy networks and eventually to Australia, where officials continue to monitor the RTMS experience. The chapter shows not only the 'translation' undertaking by South African actors, but also the 're-translation' of policy models through learning.

The role of local actors is clearly evident in the chapter by Céline Mavrot as she explores the interaction of Switzerland's sub-national (cantons) and national governments in the development and implementation of a national tobacco advertising ban. Mavrot outlines the extraordinary case of Swiss cantons collaboratively pressuring the national government to adopt international norms and implement a national ban on tobacco advertising. Unlike the other chapters in this collection, this one explores the micro-dynamics of a federal system where lower levels of government initiate action to see policy transfer and implementation taken up by the national governing framework, essentially a bottom-up process. Policy transfer was characterized by a first mover jurisdiction (Geneva) acting to support a desired and shared objective of a powerful national network of policy actors (health ministers). The study shows how cantons then cooperated in the horizontal transfer of policy, which over time built its own momentum, forcing the consideration of transfer and adoption at the national level. Local coordination and collaboration resulted in the national government achieving supranational harmonization with WHO and EU standards. The case highlights the complex interactions of policy transfer within multilevel governance systems. Here we see the willing adoption of horizontal transfer among lower level governments, yet more coercive forces shaping the adoption of policy at the national level. The case highlights that policy transfer is not necessarily a linear process nor top-down phenomena as might first appear. 
In her chapter, Carolina Milhorance explores the dual complexities of local actors and external transfer agents in Brazil's export of rural development models to Mozambique. During his terms as president, Lula da Silva (2003-2010) sought to revitalize Brazil's international leadership, particularly in Africa through South-South cooperation programs. Milhorance, using the advocacy coalition framework, argues that in fact there were competing models available for transfer, models that were championed by different coalitions of domestic Brazilian actors. She identifies a coalition of capitalist patronal agriculture integrated with international markets, and another organized around the small peasant production sector. Each of these were allied with clusters of governmental institutions and agencies, and each projected a different transfer agenda internationally. The first coalition promoted the diffusion of technological packages and a strong role for the private sector in agricultural markets. The second had an agenda of food purchases from family farmers, social protection, safety nets, and poverty reduction. Brazil's success in thwarting the global food crisis in 2008 made it a 'best practice' for the UN Food and Agriculture Organization (FAO), and other international agencies became involved in 'triangular cooperation agreements' between agricultural donors and recipients. Milhorance shows (through network analysis) how each domestic advocacy coalition in turn became allied with different international partners, and how Brazil then effectively projected two broadly different agricultural policy models. She goes further, however, in showing how these projections were translated by Mozambique authorities for local circumstances, arriving at different institutional and policy configurations, eventually privileging commercial, not family farmers. Her chapter closes with an observation very close to Delpeuch and Vassileva - the transfer of policy is about more than technical policy instruments, but also of constellations and coalitions of domestic interests behind those instruments.

While not neglecting local actors, the second set of chapters shift focus to the diversity and complexity of international and transnational actors. They move away from the conception of single international organizations acting in one country to show how, in fact, there are usually several such actors involved in the same reform project (touched on in Delpeuch and Vassileva), and typically engaged in combinations of competition and cooperation.

Ramona Coman's chapter explores the role of the US and the EU in rule of law promotion in Bosnia and Herzegovina $(\mathrm{BiH})$ and Ukraine. The rule of law is directly connected to governance and democracy, but also to economic development in the sense of stable regimes for contract law and other transactions. The US was an early proponent through its 
United States Agency for International Development (USAID), whereas the EU, the Organization for Security and Co-operation in Europe (OSCE), the Council of Europe (CoE), and the OECD became active only after the collapse of communism. She shows that while the core ideas across these actors were quite similar, their approaches differed the US was more 'political' in linking judicial reform to democracy, the $\mathrm{CoE}$ was more normative, while others were more technical. Initially, these approaches played out unsuccessfully in the two 'hard cases' of $\mathrm{BiH}$ and Ukraine, but Coman argues that this nevertheless led to policy learning. She observes greater attempts to tailor reform to specific circumstances, more effort to develop domestic 'ownership' of reform, and increased intra-European cooperation and coordination.

Laure Delcour's chapter analyzes transfer competition in the 'contested neighbourhood' of Armenia, Georgia and Ukraine, three postSoviet states that are unhappily situated on the larger geo-political chessboard between the EU and Russia. While the Coman and the Delpeuch and Vassileva chapters show some low levels of competition and coordination challenges among American and European institutions, the transfer agents and their objectives in those cases are broadly consistent. Delcour reminds us that policy transfer can be sharply competitive, as well as entangled in broader foreign policy considerations (as in Milhorance's chapter). Her case study is on food safety standards, and the initial interest in all three countries in joining the Deep and Comprehensive Free Trade Area (DCFTA) with the EU. Georgia and Ukraine signed in June 2014, but Armenia instead joined the Russiadriven Eurasian Economic Union (EAEU). Reaching a DCFTA agreement requires an ambitious and costly agenda of reform in food safety and agricultural standards, and the two systems are mutually exclusive. Joining one or the other tilts a country either towards the EU or the Commonwealth of Independent States. Delcour shows the interaction of macro- and micro-factors across the three cases. For example, while both Georgia and Ukraine showed firm 'pro-Western' stances and hence predictably opted for DCFTA, the implementation of those standards has been spotty. Armenia, on the other hand, while joining the EAEU, has actually made technical progress in meeting EU standards. As well, whereas Russia's security threats to Armenia induced it to reverse its initial support for the DCFTA, in Ukraine's case it led to the opposite. Depending on the configuration of micro-dynamics on the domestic scene, Delcour shows that similar external pressures (Russia's) can lead to contradictory outcomes.

Osmany Porto de Oliveira shifts our attention to the dynamic interaction of national and international actors engaged in South-South 
dialogue. The chapter traces the transfer and implementation of participatory budgeting policy and practices originating in Brazil to numerous African states. The transfer process was also supported by supranational organizations such as the World Bank and UN-Habitat. Participatory budgeting involves citizen participation in municipal processes of prioritizing public spending. Porto de Oliveira examines policy transfer to Mozambique, South Africa and Senegal. Each case is assessed against a framework of mechanisms known to shape and influence policy transfer. These include: (1) the circulation of individuals - the informed promoters of the policy; (2) induction - ranging from recommendations in reports to coercive conditions in funding agreements; and (3) networking - linking experts, exchanging information and ideas. Overlaying the discussion of these three factors is a thematic analysis of how translation - making the link to local context and conditions, influences transfer processes. The chapter reveals the complex interaction of local, national and international actors in the policy transfer process. It also shows the challenges that policy transfer faces when moving to implementation and the critical role that 'ambassadors of transfer' play in the local context. One notable aspect of this chapter is the insights revealed from cases that experienced success, partial implementation, or failure. Finally, this work provides a valuable insight into policy transfer across a group of developing countries that are less frequently studied.

The chapter by Federica Zardo draws attention to how processes of international negotiation and bargaining can shape the nature and content of policy transfer. She also explores the institutional structures that shape international policy negotiation processes and ultimately the policy transfer process. This case study examines the micro mechanics of the negotiations of major EU-Tunisia cooperation agreements since the launch of the Euro-Mediterranean Partnership. The chapter examines Tunisia-EU interaction over a 20-year period (1995-2015) and documents the shifting institutional structures, procedures and practices, committee systems and participants, as a small state like Tunisia engages with the ever-increasing complexity of the EU negotiation arena. The analysis considers how the organization and the characteristics of specific participants (technical expertise, authority, and experience) may influence and constrain policy transfer under such structured frameworks. The chapter also considers how this might then subsequently influence implementation and policy outcomes on the ground. Zardo argues that the negotiation architecture, predominantly defined by the EU, results in routinized and narrow bargaining where partners are viewed as recipients rather than actors shaping policy that accommodates local context. Under the EU negotiation process, policy transfer tends to be experienced as 
coercive adaptation. However, for the implementing state, benchmarking exercises and action plans were often overly technical and not well understood. Some policy areas experienced domestic political resistance to the EU templates, models and standards, and this resulted in a watering down and simplification before inclusion into local policies. Zardo concludes that these muddled compromises were only pyrrhic victories for the EU, and eventually failures in the policy transfer process.

The final chapter by Isil Erdinç and Claire Visier also examines policy transfer within the context of European enlargement. Specifically, it reviews EU policies concerning trade union rights in Turkey. While the orthodox view sees EU policy models coercively adopted by the recipient country, their analysis proposes a shift away from this rational approach. Instead, they apply a social constructivist analysis and aim to explore the transfer process from three distinct perspectives: (1) as a process of diplomatic negotiations (reflecting similar observations by Zardo); (2) as a political-administrative process shaped by planning documents and administrative action; and (3) as a framework that delivers financial assistance along with transfer and implementation. The authors claim that undertaking an analysis of the micro-mechanisms within each frame provides insight into how the content of the policy being transferred is reshaped and redefined during the transfer process. Their analysis is concerned with the instruments of the policy and the configuration of actors dealing with it. A key finding is that the definition of the specific content of the policy being transferred is in itself part of the transfer process. Actor interaction and engagement both build an understanding of the policy being transferred, but also an understanding of what this means in practice in the local context. This process of translation requires participation and engagement from the transmitting state (the EU in this case) and the receiving state (Turkey).

Together, the ten chapters in this book break new ground both theoretically and empirically. They demonstrate the complexity of policy transfer dynamics that is now a routine feature of domestic policy making in many countries. The collection of work highlights how important it is to understand the micro-dynamics of policy transfer if we are to begin to grasp the macro-effects that may then emerge as states progress to policy implementation. 